\title{
Aceleração, tempo social e cultura do consumo: notas sobre as (im)possibilidades no campo das experiências humanas
}

\author{
CARlos Victor leal Aderaldo 12 \\ CASSIO AdRIANO BRAZ dE AQUINO ${ }^{2}$ \\ MARIA de FÁtima VieIRA SEVERIANO ${ }^{2}$ \\ ${ }^{1}$ UNIVERSIDADE DE FORTALEZA (UNIFOR), FORTALEZA - CE, BRASIL \\ ${ }^{2}$ Universidade Federal do Ceará (UFC) / Programa de Pós-Graduação em Psicologia, Fortaleza - CE, Brasil
}

\begin{abstract}
Resumo
Esse artigo teórico tem como objetivo analisar as relações de tempo e da cultura de consumo na modernidade e sua repercussão nas experiências humanas, pela perspectiva crítica da administração. Para isso, foram usados autores da sociologia, psicologia, filosofia e administração, tendo em vista a complexidade e multiplicidade de saberes para abordar os temas. Para tratar consumo, autores como Horkheimer, Rosa, Bauman e Baudrillard foram citados; para tempo social, Sue, Pronovost, Durkheim; para experiência, Larossa, Maia, Perls. Esse trabalho tem como base o humanismo radical (BURREL e MORGAN, 1979) que está situado no eixo epistêmico da Matriz Crítica (PAULA, 2016) e se configura como relevante no campo das ciências administrativas, tendo em vista a contraposição que ele faz a maioria das produções na área, pois elas consideram modelos funcionalistas para estudar o consumo. Com base na abordagem dada nesse artigo, foi percebido que o modo acelerado da modernidade, elencado principalmente pela intensificação tecnológica, amplia a demanda de consumo desenfreado que se materializa pelo consumo de produtos, de serviços e de relações entre indivíduos. A sensação de escassez de tempo, juntamente com a demanda por consumir, afasta os indivíduos das experiências, resultando em constante insatisfação com o modo como a existência é operada na modernidade, exigindo criticidade no modo como o conhecimento é produzido na administração.
\end{abstract}

Palavras-chave: Cultura do consumo. Tempo social. Experiência.

\section{Acceleration, social time, and consumer culture: notes on (im)possibilities in the field of human experiences}

\begin{abstract}
This theoretical article aims to analyze the relationship between time and consumer culture in modernity, and its repercussion in human experiences, starting from a critical perspective of the administration. Authors in the areas of sociology, psychology, philosophy, and administration were used, considering the complexity and multiplicity of the knowledge around the subject. The discussion on consumption was grounded on the work by authors such as Horkheimer, Rosa, Bauman, and Baudrillard. As for social time, the theoretical framework counted on works by Sue, Pronovost, and Durkheim. Finally, the studies by Larossa, Maia, and Perls subsidized the discussion on experience. The article is based on radical humanism (BURREL and MORGAN, 1979), which is situated on the epistemic axis of the Critical Matrix (PAULA, 2016) and considered relevant in the field of administration sciences, given its opposition to most of the specific literature, since they consider functionalist models to study consumption. The study shows that the acceleration of modernity, mainly due to technological intensification, increases the demand for unbridled consumption that materializes through the consumption of products, services, and relationships between individuals. The sense of time shortage coupled with the demand for consumption drives individuals away from experiences, resulting in constant dissatisfaction with the way modernity operates, requiring criticality in the way knowledge is produced in management.
\end{abstract}

Keywords: Consumer culture. Social time. Experience.

Aceleración, tiempo social y cultura del consumo: notas sobre las (im)posibilidades en el campo de las experiencias humanas

\begin{abstract}
Resumen
Este artículo teórico tiene como objetivo analizar las relaciones de tiempo y de la cultura del consumo en la modernidad y su repercusión en las experiencias humanas, desde la perspectiva crítica de la administración. Para ello se utilizaron autores de sociología, psicología, filosofía y administración, teniendo en vista la complejidad y multiplicidad de saberes para abordar los temas. Para tratar el consumo, se citaron autores como Horkheimer, Rosa, Bauman y Baudrillard; para el tiempo social, Sue, Pronovost y Durkheim; y para la experiencia, Larossa, Maia y Perls. Este trabajo tiene como base el humanismo radical (BURREL y MORGAN, 1979) que está situado en el eje epistémico de la matriz crítica (PAULA, 2016) y se configura como relevante en el campo de las ciencias administrativas, teniendo en cuenta la contraposición que él hace en la mayoría de las producciones del área, pues estas consideran modelos funcionalistas para estudiar el consumo. A partir del enfoque dado en ese artículo se observó que el modo acelerado de la modernidad, que se centra principalmente en la intensificación tecnológica, amplía la demanda de consumo desenfrenado que se materializa a través del consumo de productos, servicios y relaciones entre individuos. La sensación de escasez de tiempo junto con la demanda de consumir aleja a los individuos de las experiencias, lo que resulta en constante insatisfacción con el modo como la existencia opera en la modernidad, exigiendo criticidad en el modo como el conocimiento se produce en la administración.
\end{abstract}

Palabras clave: Cultura del consumo. Tiempo social. Experiencia. 


\section{INTRODUÇÃO}

Transformações rápidas e significativas podem ser vistas na sociedade moderna. O modo como o tempo é concebido, as relações humanas pautadas no consumo e o reflexo desses aspectos na formação das subjetividades podem ser observados em diversas culturas ocidentais (BAUMAN, 2003; BAUDRILLARD, 2005; LIPOVETSKY, 2007). Essas culturas destacaram o trabalho em relação a outras esferas de organização social. Não é à toa - e não foi de modo repentino - que o trabalho se tornou a instituição reguladora de outros tempos sociais, dominando o modo como são concebidas as relações humanas (SUE, 1995). E foi importante que profundas transformações tecnológicas, que a instrumentalização, quantificação do tempo e que a promessa da satisfação de necessidades por meio do consumo, operassem para que isso ocorresse.

A centralidade do trabalho para a organização social não está somente no tempo dedicado a ele, mas no que ele proporciona, igualmente no tempo de não trabalho. Lazer e tempo livre são mercantilizados e fetichizados em uma lógica de consumo que captura os desejos individuais e os converte em mercadoria (SEVERIANO e ESTRAMIANA, 2012). Os próprios indivíduos se colocam como objetos de consumo uns dos outros, ao postar amor, amizade e prazer pelas redes sociais em busca de reconhecimento intersubjetivo.

Os padrões de consumo norteadores da modernidade sujeitam os indivíduos a estarem sempre em dia com as atualizações tecnológicas, a não pararem nunca de trabalhar, a se flexibilizarem ilimitadamente para atender a múltiplas demandas cotidianas. Tempos são comprimidos em diversas atividades simultâneas e a sensação de "falta de tempo" se torna comum. 0 tempo é monetarizado, comprimido e manipulado, pois é marcado pela urgência, levando a complexas e difusas organizações da temporalidade (PADILHA e JORGE, 2015). Ritmos de vida são acelerados para dar conta da aceleração tecnológica e da aceleração social, tendo impactos na produção da subjetividade (ROSA, 2003).

As culturas do hiperconsumo e do hedonismo são integradas ao contexto social, levando os indivíduos a se voltarem exclusivamente para a satisfação de seus prazeres mais imediatos, e fragilizando o sentido de coletividade e de cidadania entre eles (VALADARES, VILAS BOAS, REZENDE et al., 2016). O discurso imediatista hedonista introjetado nos indivíduos não permite adiamentos; é no hoje que se garante uma ideia de futuro, em um viés progressista e descontextualizado do passado. O descompasso entre o que é veiculado socialmente e as experiências humanas vai sendo preenchido por promessas do que ainda está por vir, e igualmente pelo consumo, e subjetividades são fragilmente constituídas como meras colagens de fragmentos carentes de reconhecimento social. Em vista disso, faz-se necessária uma discussão que possa repensar o discurso que promove o consumo desenfreado e descontextualizado, e isso pode ser feito por meio de um referencial que atue na desconstrução e desnaturalização das estratégias de vieses positivistas e funcionalistas.

Neste sentido, Padilha e Jorge (2015) ressaltam as contribuições de perspectivas críticas da administração, tais como teoria crítica nas organizações, Critical Management Studies e os Estudos Organizacionais Críticos, que rompem com o modelo funcional orientado para discursos de management, de eficiência e de eficácia organizacionais. Essa ruptura é importante na medida em que a administração precisa considerar o contexto macrossocial, macroeconômico e macropolítico, em lugar de focar somente em estratégias para obter maior rentabilidade e competitividade (PADILHA e JORGE, 2015).

Na área do marketing, Scussel (2017) ressalta que a maioria das produções enfatiza a adoção de estratégias para ampliar o consumo, mas que é necessária uma postura epistemológica distinta da compreensão de fenômenos sociais complexos, exigindo diálogo com outras fundamentações e metodologias sociológicas. A autora aponta ainda para a importância de se considerar os processos de subjetivação na sua totalidade em lugar do privilégio dado à razão objetiva, no intuito de possibilitar o avanço das pesquisas em administração.

É importante destacar que as pesquisas podem ser de cunho ou teórico ou prático. Maranhão e Vilela (2017), tal como Adorno (2009) aponta na sua obra Dialética negativa, enfatizam a importância das pesquisas práticas no campo, muito embora a maioria dos estudos em administração, baseados na teoria crítica, sejam de cunho teórico. Desse modo, a dialética negativa na administração não se dá nas polaridades da primazia do real (campo) ou da primazia da ideia (teoria). É na inter-relação estabelecida entre as duas perspectivas que há possibilidade de compreensão dos fenômenos sociais, considerando a historicidade dos discursos e das contradições que emergem de versões da realidade que se fixaram como real (MARANHÃO e VILELA, 2017).

Assim sendo, esse trabalho tem como base o humanismo radical (BURREL e MORGAN, 1979) situado no eixo epistêmico da Matriz Crítica (PAULA, 2016), visto que as categorias abordadas no artigo - cultura do consumo, tempo social e experiência 
- receberam diversas contribuições da teoria crítica desenvolvida durante o século XX com a Escola de Frankfurt. Na administração, outras pesquisas relacionaram a teoria crítica para a ampliação dos estudos da área, tais como as contribuições de Debord e a análise da sociedade do espetáculo (GORIBA, LIMA e CARRIERI, 2015), cultura hedonista e sociedade de hiperconsumo (VALADARES, VILAS BOAS, REZENDE et al., 2016) e o esvaziamento do sentido do trabalho mediante práticas gerencialistas do trabalhador (ROHM e LOPES, 2015), entre outros.

Em virtude do que foi exposto, o objetivo deste artigo é analisar as relações de tempo e da cultura de consumo na modernidade e sua repercussão nas experiências humanas, tomando-se por base a perspectiva crítica da administração. Dada a sua natureza complexa, contribuem para a abordagem multidisciplinar do tema autores da sociologia, da psicologia, da filosofia e da administração. Inicialmente será feita uma análise do tempo social com o intuito de explicitar a sua relação na formação de subjetividades. Em seguida serão apresentados os fundamentos da aceleração e da sociedade do consumo com base nos estudos da teoria crítica, pois considera-se que esses referenciais são relevantes para a compreensão e a desnaturalização dos discursos na modernidade. Por fim, refletimos sobre a experiência e o modo como ela é operada na subjetividade, destacando a necessidade de se repensarem os modos como as pesquisas sobre consumo são conduzidas no campo das ciências sociais aplicadas.

\section{Tempo Social}

O tempo constitui um objeto de pesquisa que interessa a diversas áreas do saber, tais como a Física, a Sociologia, a Psicologia, a Filosofia, a Religião. A multiplicidade de abordagens justifica-se pela complexidade desta categoria: se, por um lado, ele pode ser pensado por seus aspectos vinculados à natureza, ao espaço e aos instrumentos de medida objetivamente demarcados pelo homem, por outro, ele também pode ser visto pelo viés social e psicológico que o constitui (AQUINO, 2003).

De fato, o tempo é uma categoria complexa que dá sentido aos acontecimentos naturais e sociais (ELIAS, 1997). A sucessão de eventos naturais é nomeada com base no tempo - o tempo do dia, da noite, das estações, o que possui também caráter social, pois as vidas se organizam baseadas no tempo, segundo o tempo do plantio, da colheita, da chuva, da estiagem. Além disso, instrumentos de medidas e categorizações do tempo foram criados em cada sociedade, dando sentido e organizando os ritmos de vida. A criação dos calendários e o significado atribuído aos eventos sistematizados com o tempo podem ser observados nas mais diversas civilizações (ELIAS, 1997).

Os calendários dão sentido às tradições e aos costumes das civilizações, organizando-as e constituindo significados compartilhados por elas. Desse modo, vidas e subjetividades se formam alicerçadas em uma rede de interação simbólica. $\mathrm{O}$ tempo e suas demarcações e medições organizam a história da humanidade, pois se relacionam com os hábitos, os estilos e os modos dos grupos sociais (SEVERIANO e ESTRAMIANA, 2012).

Isso pode ser visto em diversas civilizações antigas, tal como entre os maias, cuja concepção do tempo era ordenada, fixa, lógica e circular. A organização social se dava por meio de ciclos de duração específica, retomando-se à etapa inicial da criação, após períodos contabilizados de tempo.

A partir do cristianismo, a noção de tempo foi reformulada para um modelo linear; o início se daria a partir da criação divina e terminaria com o dia do juízo final (AQUINO, 2003). A noção de linearidade corrobora os modelos históricos da compreensão do tempo e dos eventos da humanidade, pois os eventos são categorizados a partir de uma sucessão de momentos que vão sendo somados para a compreensão das sociedades.

Por sua parte, as concepções modernas de tempo envolvem seu caráter objetivo e subjetivo. No primeiro aspecto, ele pode ser compreendido por intermédio de seu caráter próprio e independente, ao considerá-lo como sucessões de eventos naturais. Subjetivamente, ele pode ser entendido pelas histórias que são descritas dos eventos sociais, que tanto o organizam quanto o criam, tendo em vista o desenvolvimento do homem e das sociedades. Durkheim (1985) afirma que o tempo é uma construção social coletiva de indivíduos que compartilham significados em comum para sua organização social. Com Durkheim a noção de tempo social ganhou importância como objeto de estudo das ciências sociais. Para o autor, cada momento histórico é demarcado por um tempo social que determina os diversos costumes e valores das civilizações.

Diferentemente de Durkheim, Sue (1995) adota a compreensão de diversos tempos sociais, ao contrário de apenas um. O tempo social dominante organiza as outras diversas atividades e tempos, tendo em vista a influência deste nos outros tempos sociais. De acordo com o autor, tempo social possui três características: 
a) é cíclico, regular e reversível. Ele antecede a constituição das sociedades e faz parte dessa história, demarcando o mito do fundador em intervalos regulares;

b) enquanto representação da história mítica, ele é organizador da duração (calendários, por exemplo);

c) tempo social é lugar de produção simbólica da sociedade.

Tudo aquilo que se relaciona ao tempo social dominante é valorizado em detrimento de outras atividades relacionadas a outros tempos sociais. A transformação das temporalidades pode ser observada relativamente ao tempo livre, o qual passou a ser dedicado também ao consumo e à produção (SEVERIANO e ESTRAMIANA, 2012), ou seja, o tempo livre foi subjugado pela cultura do consumo, expandindo as possibilidades de mercantilização de vidas e de subjetividades

Na modernidade, o tempo de trabalho se tornou o tempo social mais importante, subjugando outras temporalidades. A criação da jornada de trabalho durante a revolução industrial organizou o tempo da sociedade segundo o tempo produtivo, regulado cronologicamente pelas grandes indústrias. $\mathrm{O}$ uso dos relógios nas indústrias foi posteriormente adotado pelos trabalhadores, que transformaram seu tempo em virtude do trabalho e passaram a autorregular-se ao adotar os relógios de pulso (CHANLAT, 1996). Pronovost (1996) ressalta que essas transformações na temporalidade produziram mudanças tanto no mundo laboral quanto na organização da sociedade.

Nesse sentido, o discurso da produtividade e do trabalho logo se fazem presentes e centrais na subjetividade e na constituição das identidades humanas, sendo tudo o mais considerado "perda de tempo" e, portanto, digno de condenação. Corroborando esta ideia, Munné (1980) enfatiza que o tempo social voltado para o trabalho (tempo socioeconômico) se sobressai em relação aos outros tempos sociais. Para o autor, o tempo social pode ser entendido de quatro perspectivas: tempo psicobiológico; tempo socioeconômico; tempo sociocultural; e tempo livre.

O tempo psicobiológico é compreendido pelas necessidades fisiológicas básicas de sono, nutrição e reprodução. É um tempo individual e autocondicionado.

O tempo socioeconômico é aquele historicamente valorizado pela sociedade do trabalho. Ele se refere ao tempo para suprir necessidades econômicas fundamentais, tais como o trabalho, os estudos, e outras demandas que foram condicionadas, em sua grande maioria, pela sociedade.

O tempo sociocultural refere-se às demandas de sociabilidade resultantes dos compromissos com os sistemas de valores e culturais de uma determinada população. É uma dimensão de temporalidade que pode ser condicionada externamente e internamente pelo indivíduo.

A quarta dimensão de tempo é o tempo livre, e essa categoria deveria estar relacionada às necessidades do indivíduo, proporcionando-lhe liberdade e criatividade.

Como ressaltado anteriormente, os diversos tempos sociais foram transformados pelo tempo do trabalho, ou seja, pelo tempo socioeconômico. A supervalorização do tempo de trabalho surge na modernidade conforme as sociedades ocidentais se articulam em torno dele, reduzindo ou transformando outros tempos sociais. Nas organizações, isto se concretiza em modelos de gestão que buscam a maximização dos processos de eficiência organizacionais, reduzindo tempos mortos e minimizando a importância dos aspectos subjetivos relacionados ao trabalho (GAULEJAC, 2007; PADILHA e JORGE, 2015). Os tempos desvinculados da produção perdem relevância perante o discurso do management e da otimização dos lucros, impondo aos trabalhadores uma lógica temporal desconectada das suas necessidades físicas, psicológicas e sociais.

No Brasil, isso pode ser visto com as reformas trabalhistas pela aprovação do Decreto-lei 5.452 (BRASIL, 2017) em 14 de julho 2017, quando o tempo para se alimentar no intervalo do almoço no trabalho é flexibilizado, levando os indivíduos a mudarem seu ritmo psicobiológico para atender às demandas do capital. Muitos trabalhadores tiveram suas horas de sono reduzidas para cumprir a carga horária de trabalho, deixando de lado outros aspectos da esfera social.

Ainda que seja exigida a presença do indivíduo no local de trabalho, a pressão exercida em relação à produtividade e à supressão de outras temporalidades pela organização resulta em desconexão do trabalhador com as atividades que realiza, seja pelo cansaço, pela perda de sentido ou pela perda de saúde, entre outros motivos. Camargo (2017) destaca esse fenômeno como presenteísmo, no qual o indivíduo está presente fisicamente no trabalho, mas com a sua atenção voltada para outras questões, parcializando sua presença e dividindo sua atenção com outras necessidades objetivas e/ou subjetivas. 
A fragmentação e a parcialização do indivíduo com sua atividade estabelece um nexo relacional com as condições de trabalho e com as dimensões ambientais e organizacionais, sendo o presenteísmo motor de riscos psicossociais no trabalho (CAMARGO, 2017). A intensidade e o tempo de trabalho configuram-se como um desses riscos e se traduzem como uma temporalidade designada pela organização para cada atividade em uma jornada. $O$ desenho das tarefas ocorre de forma alheia ao trabalhador, e a incidência do culto à produtividade desconsidera tempos que são necessários à saúde, à presença e à experiência dos indivíduos. Muitos deles buscam em outras temporalidades a experiência que lhes foi subtraída pelo trabalho.

O tempo sociocultural foi transformado em mercadoria e consumo. Paralelamente, tem-se o tempo livre transformado em consumo pela indústria cultural, que mercantilizou o lazer e o converteu em objeto de adoração (PINHEIRO, RHODEN e MARTINS, 2010; SEVERIANO, 2017). O direito ao lazer transformou-se, supostamente, em mérito pelo trabalho, e ele ainda precisa ser rentável para a sociedade, que se retroalimenta com a sua mercantilização.

A centralidade do trabalho na modernidade se dá não somente pelo tempo de trabalho, mas também por o não trabalho ser vinculado às atividades que precisam ser consumidas como resultados do labor. Subjetividades são circunscritas em contextos de rápidas e perenes transformações (BAUMAN, 2003), nos quais os indivíduos buscam experiências por meio do consumo, seja de objetos anunciados midiaticamente, ou mesmo o consumo das próprias relações humanas (SEVERIANO, 2013).

Sue (1995) destaca algumas características das sociedades modernas ocidentais que foram importantes para a naturalização das transformações nos tempos sociais:

a) legitimação do valor do tempo: o tempo ganha valor econômico e é conduzido por uma lógica vinculada ao trabalho e à produção de valor;

b) medidas do tempo: o tempo é regulado e cronometrado no seu valor quantitativo. Tais medidas como dias, horas e minutos se sobrepõem à experiência subjetiva ou à compreensão qualitativa de tempo;

c) estratégias temporais: na organização das sociedades modernas, a compreensão de tempo é direcionada para o futuro. Ideias de desenvolvimento são veiculadas pelo discurso do que está por vir e do que precisa ser feito hoje para garantir o futuro;

d) horizonte temporal: as atividades individuais e coletivas são organizadas em torno do tempo social dominante; no caso, o trabalho. Projetos de vida e representação do futuro estão relacionados a essa atividade.

Essas características, aliadas ao processo de avanço tecnológico, ditam vidas que se articulam em processos de aceleração, tendo em vista satisfazer necessidades que antes nem existiam (SEVERIANO, 2013). A monetarização do tempo, que o transforma em dinheiro, direciona toda uma sociedade para a satisfação de desejos e necessidades criadas, mobilizando indivíduos para um processo mais intenso de afastamento das experiências.

\section{Teoria Crítica, Aceleração e Cultura de Consumo}

Os estudos e as contribuições da teoria crítica da Escola Frankfurt emergem em um contexto entre guerras e buscam, entre outras coisas, questionar o modo de produção do conhecimento científico ordenado, natural, determinado e positivista predominante na época. Horkheimer (1983) aponta que as teorias tradicionais, por tentarem estabelecer relações causais baseando-se em processos dedutivos, não são suficientes para entender fenômenos sociais. O caráter positivista da ciência é incapaz de compreender esses fenômenos na sua complexidade, sendo necessário um viés crítico que denote, igualmente, a influência do pesquisador na construção da pesquisa.

A teoria crítica viabilizou a desconstrução do processo positivista e cartesiano de formação do conhecimento nas ciências sociais, possibilitando uma reflexão alicerçada em uma filosofia negativa, dialética e emancipatória (GOBIRA, LIMA e CARRIERI, 2015; PAULA, 2016). Ela contribui também para as pesquisas em administração que buscam não dicotomizar a realidade social, nem a construção discursiva dessas realidades, pois, não se pode compreender o objeto de estudo isoladamente do contexto de onde ele emerge (MARANHÃO e VILELA, 2017).

Contudo artigos que têm como referencial teórico a perspectiva crítica e a filosofia negativa não foram suficientemente explorados pelo campo da administração, o qual demanda desenvolvimento teórico que sustente uma prática baseada em uma postura ético-política dos pesquisadores da área. Aportes das ciências sociais, da antropologia, da filosofia e da psicologia são necessários para ampliar as discussões que, historicamente, estiveram direcionadas para modelos funcionalistas de produção do conhecimento. Com base no exposto, procura-se, com base nos estudos da matriz crítica (PAULA, 2016), a: 
[...] ampliação de debate de instigar discussões por vezes desconfortáveis e desafiadoras da lógica dominante, trazendo à baila temas que são fundamentais ao desenvolvimento de uma sociedade mais humana e igualitária, dentro da qual a atividade empresarial seja capaz de refletir os reais interesses dessa sociedade (SCUSSEL, 2017, p. 543).

No campo das ciências sociais aplicadas, Padilha e Jorge (2015) destacam que a teoria crítica nas organizações rompe com o positivismo das teorias tradicionais, pois considera como aspectos centrais: as contradições, a ideologia dominante, as racionalidades dominantes, o contexto sócio-histórico, os processos de emancipação e a conscientização individual e coletiva. Ainda que não seja possível conseguir uma liberdade absoluta do indivíduo, tendo em vista as práticas discursivas, o contexto social, econômico e político em que ele está inserido, a teoria crítica propõe uma prática reflexiva que quebre os paradigmas estabelecidos. Assim, a perspectiva unidimensional e alienada vai sendo substituída por reflexões que promovam a emancipação e a reconfiguração dos discursos naturalizados pelo sistema vigente (PADILHA e JORGE, 2015).

É necessário, portanto, a utilização de múltiplos métodos para a apreensão dos fenômenos sociais (SCUSSEL, 2017), optando-se pelo debate entre as ciências humanas e as ciências sociais aplicadas. Serva (2017), ao realizar um panorama dos estudos em administração no Brasil, destaca oito dimensões exploradas. Dentre as dimensões, é mencionado o "debate sobre opções epistêmicas e filosóficas", que caracteriza as produções que buscam dialogar com perspectivas críticas para a ampliação dos estudos organizacionais, tais quais as metodologias da pesquisa histórica, por meio da sistematização, coleta e avaliação dos dados, enfatizando a contextualização histórico-social na produção do conhecimento da área (COSTA e SILVA, 2019). Tendo como fundamento essas perspectivas críticas apontadas, pode-se entender como se deu a naturalização do processo de aceleração vivido na modernidade, o que é central para se compreender a organização de subjetividades pautadas na cultura de consumo (ROSA, 2003; MAIA, 2017). A temporalidade é uma característica que dá sentido à ordem social e à história, tendo como consequência a influência na formação da subjetividade. A aceleração no contexto social transforma valores e comportamentos, assim como as relações estabelecidas entre os indivíduos, de modo que ritmos de vida se reconfiguram para atender aos padrões sociais criados.

Hartmud Rosa (2003) discorre sobre três formas distintas de aceleração: a tecnológica, a de mudança social e a aceleração dos ritmos de vida. Essas formas são inter-relacionadas e promovem uma retroalimentação nos processos de aceleração:

Figura 1

Formas de aceleração

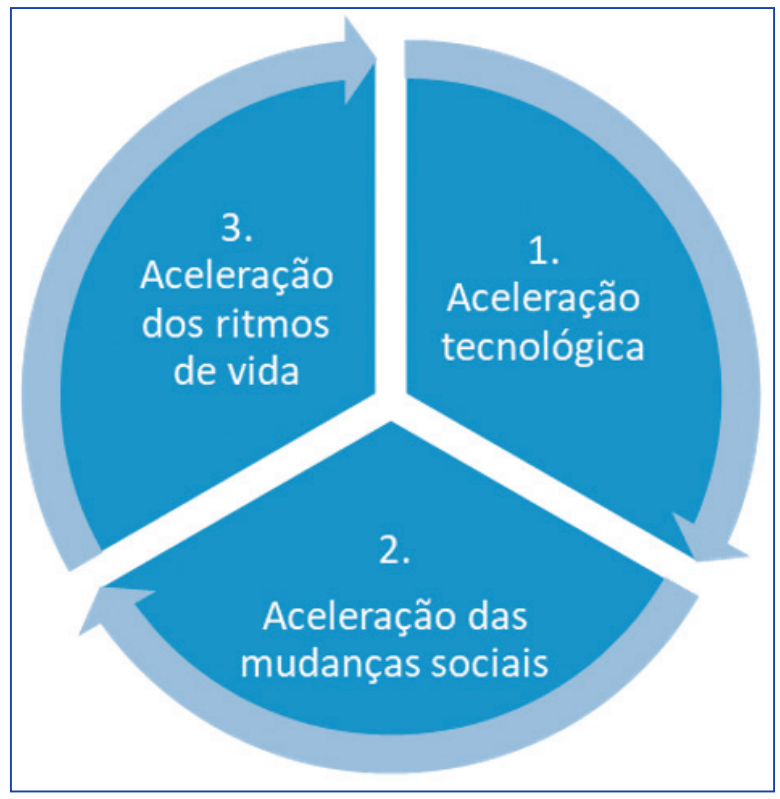

Fonte: Rosa (2003, tradução nossa). 
O processo se inicia com a aceleração tecnológica derivada dos avanços da informática, da robótica, da comunicação e dos smarthphones, entre outros. Os computadores e outras tecnologias, cada vez mais avançadas, intensificam o número de atividades que podem ser realizadas ao mesmo tempo. O objetivo social imediato é o de economizar tempo, o que fomenta mudanças nas estruturas sociais para se integrarem ao modelo de organização pautado nas multitarefas (ROSA, 2003), o que pode ser percebido em diversos âmbitos da sociedade. Os modelos produtivos eliminam os tempos mortos e intensificam o tempo do trabalho dos indivíduos (DAL ROSSO, 2017); nos meios de comunicação, as informações são apresentadas de forma rápida e simultânea, não havendo tempo para a assimilação dos conteúdos apresentados, entre outros.

Além disso, as mudanças sociais, referentes às rápidas transformações de valores e de costumes, também são influenciadas pela aceleração tecnológica. Aspectos culturais que eram válidos por muitos anos são contraídos para uma validade mais curta e imediata, de modo que as mudanças processuais em gerações diferentes são substituídas rapidamente dentro de uma mesma geração. $O$ que é válido e aceitável hoje deixa de ser valorizado em um amanhã muito próximo, exigindo maior rapidez na atualização das pessoas inseridas neste contexto (ROSA, 2003; MAIA, 2017).

A aceleração social promove a separação da experiência em relação às expectativas dos sujeitos, diminuindo a estabilidade do tempo pela compressão do presente. Se o indivíduo é incentivado a realizar diversas atividades simultaneamente com a preocupação de "não ficar para trás", o resultado disso é o esvaziamento da experiência, pois as circunstâncias da ação e dos estilos de vida perdem sentido nos intervalos de tempo cada vez menores, tendo como consequência a constante percepção de falta de tempo (ROSA, 2003). Derivado desse contexto, tem-se a aceleração dos ritmos de vida, pois, na tentativa de suprir as mudanças sociais produzidas pela aceleração tecnológica, os indivíduos aceleram suas vidas e, por meio do consumo das tecnologias buscam inibir a sensação de vazio. Assim, surge a necessidade de se passar por diversas experiências em menor unidade de tempo, o que distancia os sujeitos da própria experiência com formação de sentido (LAROSSA, 2002; MAIA, 2017).

A aceleração tecnológica tem um papel importante na mudança da relação espaço-tempo, priorizando a otimização do segundo, tendo em vista maior tempo livre para realização de outras atividades. Paradoxalmente, o que se observa é a sensação de falta de tempo pela aceleração dos ritmos de vida (MAIA, 2017), pois a quantidade de tarefas que precisam ser realizadas cresce exponencialmente a partir da aceleração tecnológica. Se antes levava-se uma manhã para escrever três a quatro cartas, atualmente são exigidas a leitura e a resposta a quarenta e-mails no mesmo período de tempo (ROSA, 2003).

A aceleração é a característica fundamental da modernidade. A ideia de que os avanços tecnológicos podem resolver uma série de problemas e de atrasos perpassa o discurso social e são naturalizados em ritmos de vida acelerados (SEVERIANO, 2013; MAIA, 2017). Os fast-foods, a internet, a robótica, os celulares e a hiperconexão ofertada dão a sensação de facilidade e de rapidez na conexão, com a satisfação imediata de qualquer necessidade. Se antes havia uma demora na entrega da correspondência, atualmente e-mails, mensagens e imagens são enviadas e recebidas instantaneamente, levando o indivíduo a ter sempre a suposta oportunidade de saber de tudo o que ocorre em qualquer lugar, a qualquer hora.

As relações e os costumes sociais vão se transformando na medida em que a tecnologia substitui encontros presenciais por conferências à distância, nas quais o afeto presencial é trocado por likes e comentários nas redes sociais, ou também no momento que as pessoas substituem o relato da própria experiência por histórias de sucesso ou de felicidade construídas nas redes sociais para serem consumidas pelo outro. São criadas condições de perda da capacidade de olhar o outro para além da mercadoria que ele se tornou. Em paralelo, o indivíduo perde a capacidade de se ver nesse processo, pois paulatinamente essas práticas são absorvidas pelo sujeito, estabelecendo condições para a ruína da capacidade de interpretar e de refletir sobre a realidade (VALADARES, VILAS BOAS, REZENDE et al., 2016).

Bauman (2001) ressalta que o consumo, cujo propósito anteriormente era o de satisfazer as necessidades de sobrevivência biológicas e sociais dos indivíduos, deixa de ser relevante a partir do momento que essas necessidades são satisfeitas. Para o autor, o consumo passa a ser o propósito da organização social na modernidade, sendo automotor do que é conhecido como sociedade do consumo, que proclama a impossibilidade de satisfação das necessidades e a continuidade do estado de tensão na busca de satisfazê-las.

Os indivíduos passam, então, a consumir estilos de vida pré-formatados, transformando a si mesmo e considerando os outros como mercadoria. As relações de consumo se estabelecem como ordem social predominante, e a sensação de vazio, assim como a busca de preenchê-lo se tornam comuns em uma sociedade saturada de subjetividades sustentadas em imagens vazias.

Severiano (2017) aponta que a sociedade e a cultura do consumo estão além dos produtos ou serviços produzidos pelo capitalismo. De fato, o consumo estende-se para a produção de signos marcadores de subjetividades, que prescrevem modos 
de ser, de pensar e de sentir. Nele, são operados mecanismos de socialização, de exclusão e de inclusão social, tendo em vista o lugar de reconhecimento intersubjetivo que ele promove.

A autora define cultura de consumo:

[...] como aquela em que o consumo se estabelece como fonte de referência identitária e fator preponderante de produção de subjetividades e de reconhecimento social; uma vez que também se consomem imagens, lugares, pessoas e estilos de vida que, por sua vez, significam e prescrevem determinados ideais, modos de ser, estar, amar e sentir (SEVERIANO, 2017, p. 85).

Rosa $(2003,2017)$ destaca ainda que somos conduzidos a consumir cada vez mais e nos tornamos mercadoria dos estilos de vida que criamos. A busca é de superar aquilo que foi consumido no ano anterior, e essa coerção afeta a autocompreensão do ethos individual, levando o indivíduo a uma sensação de incompletude e a uma ânsia por um tipo de crescimento distanciado de si.

O processo operado pelo neoliberalismo surge nas diversas formas de capitalismo absorvido em subjetividades, que mudam seus estilos de vida para fazer parte dele, assim como replicam mecanismos que transformam a si e aos outros em objetos de consumo (BAUMAN, 2001; BAUDRILLARD, 2005; ROSA, 2017).

Como isso se tornou possível na modernidade?

Rosa (2017) alerta para as patologias do capitalismo, que modifica os estilos de vida, gerando irracionalidade, destemporalização e alienação. Para o autor, a irracionalidade surge como o imperativo do progresso e do crescimento. Ainda que muitos recursos tenham se esgotado ou que muito tenha sido feito, a ideia que norteia as subjetividades é a de que é necessário alcançar crescimento e progresso constantemente e a todo custo, descontextualizando os processos já conquistados. A história, os antepassados e as tradições construídas durante anos deixam de ser consideradas, pois passam a ser percebidas como obsoletas, ultrapassadas ou em desuso, movimentando a sociedade para a direção de um progresso e de um crescimento que se tornam passado rapidamente.

Já a destemporalização refere-se aos fenômenos da aceleração e de que tudo precisa ser feito e planejado hoje para a conquista da felicidade ou estilo de vida desejado no futuro, ainda que o amanhã possa mudar completamente o que havia sido imaginado para esse futuro, ou, em outras palavras, aceleração das mudanças sociais (ROSA, 2003, 2017).

A alienação é abordada como intensificação não só da alienação dos meios de produção, mas também uma alienação de si. Desejos individuais são desestruturados em deveres coletivamente afirmados: o indivíduo não pode deixar de ter o celular de última geração, de usar redes sociais, de utilizar tecnologias mais avançadas para "ganhar tempo" e não pode se recusar a se flexibilizar diante das demandas de trabalho. Relativamente ao último aspecto, Sennett (1999) destaca a transformação das vidas em torno das demandas do novo mundo do trabalho, que mudam também o modo como os indivíduos se relacionam ou constituem suas subjetividades. Para o autor, as relações de curto prazo e as intermediações tecnológicas fragilizaram igualmente os vínculos sociais que são desenvolvidos no trabalho, transformando indivíduos em engrenagens ou partículas de um processo que se encerra quando o projeto ou a atividade não é mais necessária. Trabalhadores e histórias de vida se tornam obsoletos em sociedades aceleradas e de curto prazo.

Ainda sobre as patologias do capitalismo, Rosa (2017) reitera que o modo como o sistema se constituiu nos afasta de nós mesmos, das nossas experiências constituidoras de sentido. $O$ debate sobre essas patologias surge como possibilidade de resgate das experiências individuais, em lugar de acessos rápidos e líquidos da existência humana.

\section{Notas sobre a Experiência}

A sociedade moderna impôs modos de vida acelerados voltados para o desempenho e para o ideal de felicidade anunciados em forma de consumo. $O$ "não ter tempo a perder" dissimula a responsabilização individual pelos fracassos de uma sociedade sintomática. Kehl (2009) contrapõe as narrativas de liberdade, de autonomia, de felicidade aos adoecimentos emocionais que surgem em forma de depressão na atualidade. A crescente manifestação dos adoecimentos revela patologias que não devem ser pensadas isoladamente, mas como patologias sociais (KEHL, 2009).

Justamente diante de um cenário com várias informações e direcionamentos da sociedade, adoecemos e nos perdemos no sentido da existência. Afogados em racionalizações e palavras, aprendemos a repetir não só pensamentos ou frases, mas 
também significados. Esses são cunhados socialmente e formatados no cotidiano, direcionando escolhas que nos distanciam dos sentidos construídos pelo indivíduo.

"[E]xperiência é aquilo que nos passa, nos acontece, nos toca" (LARROSA, 2002, p. 21). Muitas coisas nos passam, mas poucas nos tocam. Informações vão dando lugar às experiências com sentido, e nomeamos a existência de acordo com algo externo a nós. $\mathrm{O}$ trabalho, a escola, a família, o relacionamento amoroso, os amigos e o lazer, entre outros, ganham configuração valorativa a partir diante do que é esperado pela sociedade do consumo. Neste "esperado" por parte da sociedade do consumo, vamos repetindo valores e práticas culturais que pouco dialogam com a experiência com sentido.

São diversos os mecanismos contemporâneos de destruição dessas experiências. A própria aceleração, o excesso de informação e os ditames culturais vão afastando o sujeito de si mesmo. A informação se torna em opinião enquanto reação subjetiva àquilo que nos acontece, mas a opinião não é a experiência, a qual exige engajamento real e apropriação do indivíduo sobre o próprio existir.

O viver sem existir ou o ter informações sem experimentar são internalizados enquanto possibilidades de vida dos sujeitos imersos nas acelerações. O sabe(o)r é deixado de lado nas repetições, e esse "deixar de lado" a própria experiência é afirmado como condição de sobrevivência na contemporaneidade.

No entanto, a morte subjetiva se presentifica quando não há questionamento sobre essa velocidade à qual todos estamos sujeitos. Quando se naturaliza a aceleração contemporânea, percebe-se a transformação do ser humano em um autômato ansioso, que não necessariamente sofre profundamente, mas pouco experimenta a vida criativa (PERLS, 1988). É como se o experimentar-se fosse deixado para a pós-aceleração, mas esta nunca termina por si mesma. É necessário que o indivíduo ressignifique o sabor pelas coisas e pela vida.

Larrosa (2002) afirma que a experiência exige uma parada; parar para pensar, para olhar, para escutar. Uma parada para saborear, sentir, viver. Deixar-se atravessar, perpassar, suspender. Questionar e buscar algo particular que faça sentido para esse sujeito. A experiência não é composta de informações externas ao sujeito, e sim implica transformar o que é externo em interno, transformando o externo em algo próprio, singular. Nesse sentido, há um reencontro com as necessidades individuais que são pensadas, sentidas e vividas pela pessoa na sua particularidade.

Para o autor, a experiência é o caminho para a transformação naquilo que se é, e não no que dizem que temos de ser. É algo que exige abertura para afirmar o que é fundamental para si, que não seja ditado exclusivamente pelo cenário externo. Exige uma outra postura diante da existência; uma postura de respeito com a própria forma de ser. Abrir mão das formatações e se colocar como autor da existência; ser protagonista e não coadjuvante da vida.

Apropriar-se de si exige essa ousadia fundamental, assim como exige questionamentos das verdades externas impostas. Apropriar-se de si pode ser desafiador, mas, ao mesmo tempo, é um resgate da experiência com sentido, afastando as mortes subjetivas às quais somos diariamente expostos. Ritmos de vida externos ao sentido individual, produtos e serviços consumidos de forma ativa ou passiva pelas pessoas, que não tiveram a oportunidade de questionar o próprio querer, são condições de vida perpassadas por uma indústria cultural que nos transforma em produtos, e como tais nos consumimos mutuamente.

Para além da perspectiva imediatista, acelerada e fugaz, tem-se a urgência de desacelerar para reaprender os sabores. Movimentos que buscam slowfood, slowlife e mindfulness, entre outros, surgem como aspectos necessários para a reintegração das experiências. Embora estejamos imersos no contexto que gera nos indivíduos a sensação de "fome temporal", ou seja, de ânsia por realizar várias atividades ao mesmo tempo, reduzindo a experiência presente (MAIA, 2017), torna-se imperativo que tenhamos criticidade para nos reinventarmos na sociedade hiperacelerada. O resgate da experiência pressupõe justamente o reconhecimento de nossos antepassados e das tradições que nos constituíram, assim como a possibilidade de ter projetos futuros. A compressão do presente em instantes fragmentados é própria dos tempos acelerados. Assim, a experiência demanda uma distensão temporal, na qual passado, presente e futuro são reconhecidos. 


\section{CONSIDERAÇÕES FINAIS}

A construção de um ethos voltado para as experiências singulares exige uma reflexão crítica sobre o contexto social em que vivemos. O tempo social dominante na modernidade pode ser entendido pela centralidade do trabalho, e isso se dá de duas formas: por um lado, tem-se a maior parte do tempo dedicado a ele e, por outro, o tempo livre, capturado pelo consumo, passou a ser regido pela mesma lógica instrumental e concorrencial do trabalho.

Subjetividades são, então, delineadas conforme o consumo que se estabelece como categoria fundante das atividades sociais. Não apenas produtos são consumidos, mas os próprios indivíduos se tornam objetos, valendo-se de reconhecimento em redes sociais em relação ao estilo de vida, likes, selfies, padrões de amizade, de felicidade e de amor. Torna-se necessário estar sempre atualizado para não se perder tudo aquilo que as múltiplas atividades oferecem, ainda que essa imposição da atualização não seja contextualizada nos processos de aceleração tecnológica, aceleração das mudanças sociais e aceleração dos ritmos de vida na sociedade.

É nesse sentido que experiências, tal como concebemos à luz do pensamento de Larossa, são deixadas de lado, pois exigem tempo, sabor e presença. Como ter experiências em uma sociedade voltada para o consumo, para o mais inovador, para o mais moderno, para o simultâneo, para o superconectado e para o futuro? Nessas condições a individualidade se perde em uma rede de relações dotadas de significados coletivamente compartilhados, mas que não têm sentido por não ter o sabor da experiência que poderia ser vivida pelo indivíduo.

No campo das ciências sociais aplicadas, a reflexão sobre as temporalidades, aceleração e cultura do consumo é necessária, igualmente, para a percepção crítica de modelos de gestão que se apresentam como inovadores. Em alguns momentos, esses modelos de gestão atuam na replicação e no fortalecimento dos processos de aceleração e de consumo que alienam e assujeitam os indivíduos da experiência. Discursos de management, de eficiência e de eficácia alienam sentidos que são fragmentados por não serem integrados na particularidade, na história e nos valores daquela pessoa.

Para fazer parte de organizações que sustentam as práticas de gestão, os trabalhadores são incentivados a renunciar às suas próprias subjetividades, valendo-se de modelos gerencialistas que promovem a sua precarização. $\mathrm{O}$ que ocorre de várias formas, tais como o fornecimento de recursos tecnológicos, o aprimoramento das estratégias que incentivam o consumo e a concomitante imposição de tempos que buscam delinear o trabalho para maior produtividade, gerando um descompasso e uma constante sensação de não dar conta das atividades e das atualizações do mercado. Assim, os modelos funcionalistas e positivistas na administração foram predominantes, fomentando os estudos das estratégias e do avanço tecnológico a favor da produtividade e em detrimento da presença e das experiências dos trabalhadores, ocasionando presenteísmo e descompasso nas temporalidades.

Nesse sentido, o que se observa é que as perspectivas crítica, dialética e negativa ainda são incipientes na administração. A contextualização histórico-social, crítica e comprometida em compreender as transformações na sociedade é importante na medida em que ela aponta para o compromisso ético-político dos pesquisadores, que devem buscar compreender a realidade de forma dialética em lugar de modo cartesiano. É por meio desse entendimento que se tornam possíveis as mudanças necessárias do discurso que afasta os indivíduos das experiências.

Aportes teóricos e metodológicos de outras ciências, tais como a sociologia, a psicologia e a história, podem fornecer subsídios para a dilatação dos estudos em administração. O diálogo com pesquisadores e produções de outras áreas tende a desenvolver perspectivas não exploradas pelas diversas áreas do conhecimento, tanto nas pesquisas de cunho teórico, como nas pesquisas empíricas.

Os autores reconhecem que muitos aspectos da pesquisa podem e devem ser aprofundados. Além das próprias categorias teóricas apresentadas, outros estudos podem ser conduzidos para ampliar a noção de aceleração, de cultura de consumo e de experiência em determinados grupos sociais. Por exemplo, essas categorias relacionam-se aos jovens, considerando classes socioeconômicas distintas? Como se constroem essas categorias com grupos específicos de trabalhadores, tais como os que trabalham diretamente com comunicação social, mídias sociais ou mesmo teletrabalhadores? Quais outras perspectivas teóricas e metodológicas podem ser adotadas para a compreensão das experiências na modernidade? Como esse processo se desenha com os trabalhadores informais?

Tanto pesquisas qualitativas, quantitativas ou mistas podem ser realizadas para elucidar esses aspectos. 


\section{REFERÊNCIAS}

ADORNO, T. Dialética negativa. Rio de Janeiro: J. Zahar, 2009.

AQUINO, C. B. Tiempo y Trabajo: un análisis de la temporalidad laboral en el sector de ocio - hostelería y turismo - y sus efectos en la composición de los cuadros temporales de los trabajadores. 2003. 459 f. Tese (Doutorado em Psicologia Social) - Universidad Complutense de Madrid, Espanha, 2003.

BAUDRILLARD, J. A sociedade de consumo. Lisboa: Edições 70, 2005.

BAUMAN, Z. Consuming Life. Journal of Consumer Culture, Oxford, v. 1, n. 1, p. 9-29, 2001.

BAUMAN, Z. Modernidade líquida. Rio de Janeiro: Zahar, 2003.

BRASIL. Decreto-lei n. 5.452 de 14 de julho de 2017. Reforma Trabalhista, Brasília, DF, jul. 2017.

BURRELL, G.; MORGAN, G. Sociological paradigms and organizational analysis. Elements of the sociology of corporate life. Vermont: Ashgate, 1979.

CAMARGO, M. L. Presenteísmo: denúncia do mal-estar nos contextos organizacionais de trabalho e de riscos à saúde do trabalhador. Revista Laborativa, São Paulo, v. 6, n. 1 (esp.), p. 125-146, 2017.

CHANLAT, J.-F. (Org.). 0 indivíduo nas organizações: dimensões esquecidas. São Paulo: Atlas, 1996.

COSTA, A. S. M.; SILVA, M. A. C. A Pesquisa Histórica em Administração: uma Proposta para Práticas de Pesquisa. Administração: Ensino e Pesquisa, Rio de Janeiro, v. 20, n. 1, p. 90-121, 2019.

DAL ROSSO, S. $\mathbf{O}$ ardil da flexibilidade: os trabalhadores e a teoria do valor. São Paulo: Boitempo, 2017.

DURKHEIM, E. La división del trabajo social. Barcelona: Planeta, 1985.

ELIAS, N. Sobre el tiempo. México: Fondo de Cultura Económica, 1997.

GAULEJAC, V. Gestão como doença social: ideologia, poder gerencialista e fragmentação social. São Paulo: Ideias \& Letras, 2007.

GOBIRA, P.; LIMA, O.; CARRIERI, A. Uma "sociedade do espetáculo" nos/dos estudos organizacionais brasileiros: notas críticas sobre uma leitura incipiente. Cadernos EBAPE.BR, Rio de Janeiro, v. 13, n. 2, p. 257-285, 2015.

HORKHEIMER, M. Teoria tradicional e teoria crítica. In: CIVITA, V. (Ed.). Textos escolhidos: Benjamin, Horkheimer, Adorno, Habermas. São Paulo: Abril Cultural, 1983. p. 117-154. (Os Pensadores).

KEHL. M. R. O tempo e o cão: a atualidade das depressões. São Paulo: Boitempo, 2009.

LAROSSA, J. B. Notas sobre a experiência e o saber da experiência. Revista Brasileira de Educação, Campinas, n. 19, 2002.

LIPOVETSKY, G. A felicidade paradoxal: ensaio sobre a sociedade de hiperconsumo. São Paulo: Companhia das Letras, 2007.

MAIA, A. F. Aceleração: reflexões sobre o tempo na cultura digital. Impulso, Piracicaba, v. 27, n. 69, p. 121-131, 2017.

MARANHÃO, C. S.; VILELA, J. R. de P. X. A imanência entre a teoria crítica e a pesquisa empírica: contribuições para os estudos organizacionais. Organizações \& Sociedade, v. 24, n. 82, p. 476-490, 2017.
MUNNÉ, F. Psicosociología del tiempo libre: un enfoque crítico. México: Trillas, 1980.

PADILHA, V.; JORGE, T. M. A sociologia e o mal-estar na formação de administradores. In: PADILHA, V. (Org.). Antimanual de gestão. São Paulo: Ideias\&Letras, 2015. p. 321-354.

PAULA, A. P. P. Para além dos paradigmas nos Estudos Organizacionais: o Círculo das Matrizes Epistêmicas. Cadernos EBAPE.BR, Rio de Janeiro, v. 14, n. 1, p. 24-46, 2016.

PERLS, F. A abordagem gestáltica e testemunha ocular da terapia. 2. ed. Rio de Janeiro: LTC, 1988.

PINHEIRO, K. F., RHODEN, I.; MARTINS, J. C. O. A experiência do ócio na sociedade hipermoderna. Revista Mal-estar e Subjetividade, Fortaleza, v. 10, n. 4, p. 1131-1146, 2010.

PRONOVOST, G.; Sociologie du temps. Bruxelles: De Boek Université, 1996.

ROHM, R. H. D.; LOPES, N. F. O novo sentido do trabalho para o sujeito pós-moderno: uma abordagem crítica. Cadernos EBAPE.BR, Rio de Janeiro, v. 13, n. 2, p. 332-345, 2015.

ROSA, H. Social Acceleration: Ethical and Political Consequences of a Desynchronized High-Speed Society. Constellations, v. 10, n. 1, p. 3-33, 2003.

ROSA, H. Contra a invisibilização de um "poder fatídico": apelo à renovação da crítica do capitalismo. Tradutor: Arthur Bueno. Perspectivas, São Paulo, v. 49, p. 17-36, 2017.

SCUSSEL, F. B. C. Poder, paradigmas e domínio na pesquisa em marketing no Brasil: uma análise da produção nacional da disciplina a partir das matrizes epistêmicas. Administração: ensino e pesquisa, Rio de Janeiro, v. 18, n. 3, p. 518-557, 2017.

SENNETT, R. A Corrosão do caráter: consequências pessoais do trabalho no novo capitalismo. Rio de Janeiro: Record, 1999.

SERVA, M. Epistemologia da administração no Brasil: o estado da arte. Cadernos EBAPE.BR, Rio de Janeiro, v. 15, n. 4, p. 741-750, 2017.

SEVERIANO, M. F. V.; ESTRAMIANA, J. L. A. "Tempo livre" e "tempo do trabalho": a dissolução das fronteiras temporais. Cuadernos de Psicologia, Barcelona, v. 14, p. 67-76, 2012.

SEVERIANO, M. F. V. A juventude em tempos acelerados: reflexões sobre consumo, indústria cultural e tecnologias informacionais. Política \& Trabalho (Online), João Pessoa, v. 1, p. 271-286, 2013.

SEVERIANO, M. F. V. Aceleração Social e Cultura Digital: novas formas de dominação. Revista Comunicações, Piracicaba, v. 24, n. 2, p. 83-101, 2017.

SUE, R. Temps et ordre social. Paris: PUF, 1995.

VALADARES, J. L. et al. O “cidadão hedonista": diálogos sobre consumo e cidadania na sociedade contemporânea. Cadernos EBAPE.BR, Rio de Janeiro, v. 14, n. 4, p. 966-983, 2016. 
Cassio Adriano Braz de Aquino

ORCID: https://orcid.org/0000-0001-8651-1634

Doutor em Psicologia Social pela Universidad Complutense de Madrid (UCM); Professor adjunto na Universidade Federal do Ceará (UFC), Fortaleza CE, Brasil. E-mail: brazaquino@ufc.br

Maria de Fátima Vieira Severiano

ORCID: https://orcid.org/0000-0002-8793-6658

Doutora em Ciências Sociais Aplicadas à Educação pela Universidade Estadual de Campinas (UNICAMP); Professora titular na Universidade Federal do Ceará (UFC), Fortaleza - CE, Brasil. E-mail: fatimaseveriano@gmail.com 